\title{
黄土高原植被恢复与生态系统土壤保持服务价值增益 研究
}

以延河流域为例

\author{
朱 青, 周自翔*, 刘 婷, 白继洲
}

西安科技大学测绘科学与技术学院, 西安 710054

摘要: 为探究黄土高原地区退耕还林(草)工程 (1999) 实施后植被恢复的生态效益,选择黄土高原延河流域为研究区,利用趋势 线分析法、SWAT(Soil and Water Assessment Tool) 水文模型和生态系统服务价值评价方法(市场价值法、机会成本法、恢复费用 法和影子工程法等),重点分析 2000-2015 年该区域植被恢复状况及其对土壤保持的作用,并评估生态系统服务价值的提升效 应。研究结果表明: (1) 退耕还林(草)工程实施后,延河流域植被覆盖均呈增加趋势, 植被恢复显著; (2) 植被恢复对土壤侵蚀 的抑制作用明显。在没有植被覆盖的条件下,土壤极易发生侵蚀, 且侵蚀模数大; 从该工程实施以来, 2001一2014 年土壤保持 量具有不同程度的增幅, 表明多年来流域治理取得一定的成效; (3) 流域植被覆盖以中覆盖为主, 土壤保持量以低保持为主。 不同植被覆盖下土壤保持量存在差异。其中, 中低、中、中高覆盖能有效保持土壤; (4) 生态系统土壤保持服务价值时空分布特 征明显。流域年均 $(2000-2015)$ 土壤保持服务价值为 $3.64 \times 10^{8}$ 元,生长季月均土壤保持服务价值为 $6.06 \times 10^{7}$ 元,生态系统土 壤保持服务价值显著提升。时间尺度上,生态系统土壤保持服务价值受降水因素影响; 空间尺度上,流域生态系统土壤保持服 务价值空间差异大,具体表现为下游残塬平梁沟壑区最高, 上游山地区次之, 中游梁峁丘陵沟壑区最低。通过研究延河流域植 被恢复状况以及定量评估土壤保持服务价值, 不仅阐明了退耕还林(草) 工程带来的巨大生态效益, 同时也为流域乃至黄土高 原的水土流失治理工作提供一定的参考作用。

关键词:退耕还林 (草) ; 植被恢复; 生态系统服务; 土壤保持; 黄土高原

\section{Vegetation restoration and ecosystem soil conservation service value increment in Yanhe Watershed, Loess Plateau}

ZHU Qing, ZHOU Zixiang ${ }^{*}$, LIU Ting, BAI Jizhou

College of Geomatics, Xi'an University of Science and Technology, Xi'an 710054, China

\begin{abstract}
In order to explore the ecological benefits of vegetation restoration after the implementation of the Grain for Green Project (GFGP) in 1999, this study selected the Yanhe Watershed in the Loess Plateau as the study area. By using the trendline analysis, SWAT (Soil and Water Assessment Tool) Model and the evaluation approach of ecosystem services (including market value, opportunity cost, restoration cost, and shadow project approaches), the paper analyzed the vegetation restoration status and its effect on soil conservation after the implementation of the GFGP, and assessed the effect of ecosystem service value enhancement. The results showed that: (1) since the GFGP was implemented, the vegetation recovery effect has been remarkable, which was specifically reflected in the increasing trend of vegetation coverage in the

基金项目: 国家自然科学基金资助项目 (41771576); 陕西省自然科学基础研究计划资助项目(2018JM4010); 国家自然科学基金国际(地区)合作 与交流项目 (合作交流-NSFC-NRF (中韩)) (41811540400) ; 西安科技大学博士启动金项目(2017QDJ040)

收稿日期:2020-06-12; 网络出版日期:2021-01-27

*通讯作者 Corresponding author.E-mail: zhouzixiang@ xust.edu.cn
\end{abstract}


Yanhe Watershed from 2000 to 2015. (2) The effect of vegetation restoration on soil erosion was obvious. Without vegetation cover, the soil is prone to erosion with the large erosion modulus. Taking 2000 as the base year when the GFGP was implemented, the soil conservation from 2001 to 2014 has increased to varying degrees, indicating that the watershed management has achieved certain outcomes over the years. (3) The vegetation cover in the watershed is dominated by medium vegetation cover, and the soil conservation is dominated by low soil conservation. There are differences in soil conservation under different vegetation cover. Among them, medium-low, medium and medium-high vegetation cover can effectively maintain the amount of soil. (4) The temporal and spatial distribution characteristics of the value of the ecosystem soil conservation services are obvious. From 2000 to 2015, the annual average soil conservation service value of the watershed was $3.64 \times 10^{8}$ yuan, and the monthly average soil conservation service value was $6.06 \times 10^{7}$ yuan during the growing season. The value of the ecosystem soil conservation service increased significantly. On the temporal scale, the precipitation is an important factor in the value of the ecosystem soil conservation service; on the spatial scale, the spatial differences in the value of ecosystem soil conservation service in the watershed is large, which is specifically manifested as the highest in the downstream, followed by the upstream, and the lowest in the middle-stream. This study not only clarified the huge ecological benefits brought by the GFGP, but also provided a certain reference role for the soil and water loss management in the watershed and even the Loess Plateau.

Key Words: Grain for Green Project; vegetation restoration; ecosystem services; soil conservation; the Loess Plateau

黄土高原是中国“两屏三带”生态安全格局的重要组成部分 ${ }^{[1-2]}$,该地区沟龳纵横,水土流失严重。水土 流失过程会破坏原有土壤结构,降低土地生产力,造成人民财产损失,同时在流域范围内淤积河道,造成面源 污染,加重洪涝和干旱灾害等潜在威胁,已成为全球普遍关注的生态环境问题之一 ${ }^{[3-4]}$ 。为控制黄土高原水 土流失,该地区自 20 世纪 70 年代起开始实施一系列水土保持治理措施 ${ }^{[5]}$ 。退耕还林( 草) 工程 (1999) 实施 后, 黄土高原地区植被覆盖度大幅增加, 有效降低了该地区水土流失的危害。因此, 研究该地区植被恢复与土 壤侵蚀之间的相互关系引起众多学者的关注。植被覆盖对土壤侵蚀的影响研究主要集中于植被的防蚀功效、 减水减沙效应。其中, 植被冠层消减了雨滴动能, 地表覆被物分散了径流动能, 根系提高了土壤抵抗径流侵蚀 能力 ${ }^{[6]}$, 并且不同的植被类型能在不同程度上减轻土壤侵蚀的危害。植被恢复具有延长坡面产流时间、增加 人渗、减少产流产沙的作用 ${ }^{[7]}$ 。程复 ${ }^{[8]}$ 研究指出退耕还林 (草) 工程实施后, 2008 年黄土丘陵沟壑区所有流 域单元的输沙模数整体平均降低 $54 \%$, 土壤侵蚀程度明显减弱; 赵巧巧 ${ }^{[9]}$ 研究发现黄土高原地区流域年均归 一化植被指数 (Normalized Difference Vegetation Index, NDVI) 和年均输沙量呈现出负相关的关系; 王怡菲 ${ }^{[10]}$ 研究表明当退耕还林 (草) 面积增加 $1 \%$, 流域含沙量每立方米减少 $1.894 \mathrm{~kg}$; 陈浩 ${ }^{[11]}$ 研究提出以植被恢复为主 的退耕还林(草)工程对黄土高原地区北洛河流域土壤侵蚀减少的贡献率为 $85 \%$ 。另一方面,部分学者 ${ }^{[12-14]}$ 研究土壤侵蚀对植被的影响后, 发现土壤侵蚀过程会降低土壤的持水能力和养分积累, 影响植被群落的发育 和演替,并通过侵蚀过程的机械力对植物产生干扰和破坏。

退耕还林(草)工程距今已实施二十余年,植被恢复能够抑制土壤侵蚀, 改善生态环境,促进生态系统服 务的提升, 同时,生态系统服务功能的提升有利于植被恢复。由此可见,植被恢复的生态环境效应及其带来的 一系列人类福祉是维持区域可持续发展的关键因素。目前植被与土壤侵蚀的关系方面已有大量研究,但关于 黄土高原植被格局及其对土壤侵蚀的影响和植被恢复带来的生态效益尚未明确。此外,生态系统服务的提升 也是研究的热点。鉴于此,本文以黄土高原延河流域为研究对象,探讨 2000-2015 年该区的植被恢复状况, 并借助 SWAT (Soil and Water Assessment Tool) 模型估算土壤侵蚀量和土壤保持量,揭示植被格局对土壤侵蚀 的影响, 定量研究植被恢复带来的生态系统土壤保持服务价值增益, 对今后植被建设和水土流失治理工作以 及生态补偿具有一定的理论和实际指导意义。 


\section{1 研究区概况与数据来源}

\section{1 研究区概况}

延河流域 $\left(36^{\circ} 27^{\prime}-37^{\circ} 58^{\prime} \mathrm{N}, 108^{\circ} 41^{\prime}-110^{\circ} 29^{\prime} \mathrm{E}\right)$ 作为黄土高原丘陵沟壑区的典型流域,地表破碎,沟间 地以丘陵为主,梁、峁状丘陵大约占流域沟间地的 $80 \%$, 为流水侵蚀和重力侵蚀提供了 “有利” 的地貌条件。 流域处于东部季风湿润区与内陆干旱区的过渡地带, 年降水量偏少, 多年平均降水量为 $520 \mathrm{~mm}$, 降水季节分 配不均, 集中于夏季, 秋季次之, 春季较少, 冬季有少量降雪。该流域水土流失严重, 河流含沙量大, 泥沙多为 悬移质, 水土流失面积接近流域总面积的 $80 \%$, 是黄河中游水土流失最严重的区域之一。延河流域的植被特 性也具有过渡性，随着植被类型、覆盖度等生态特点的不同，植被抗蚀作用也有所差异。因此本文选取延河流 域作为研究区域,其位置分布如图 1 所示。

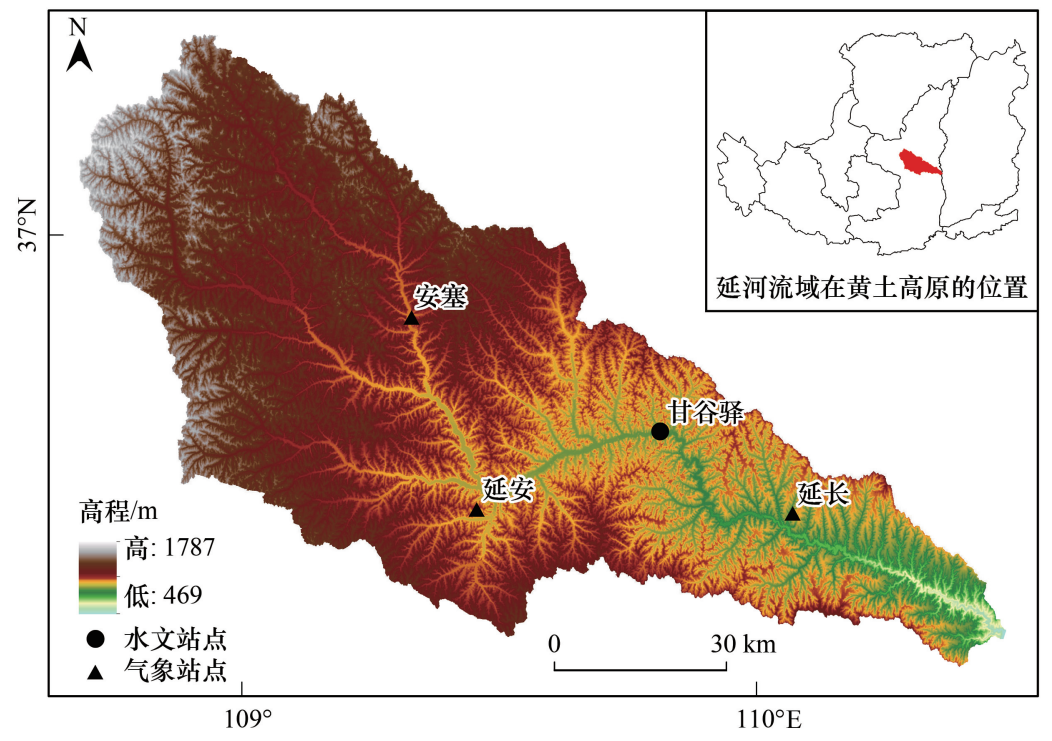

图 1 研究区的地理位置

Fig.1 Geographical location of the study area

\section{2 数据来源与处理}

本文使用的数据包括 NDVI 数据及构建 SWAT 模型所需的数字高程模型 (Digital Elevation Model, DEM)、 土地利用数据、土壤数据、水文数据和气象数据。(1) NDVI 数据采用美国地质勘探局 ( http://glovis. usgs. gov/) 提供的 MODIS 植被指数产品-MOD13Q1, 研究选用的时间范围为 2000-2015 年, 每年 23 期影像, 共 368 期, 时空分辨率为 $16 \mathrm{~d}$ 及 $250 \mathrm{~m}$ 。利用 MRT(MODIS Reprojection Tools) 软件对该数据产品进行格式转换和 投影转换,将 HDF 格式转换成 TIFF 格式,并将 SIN 投影转换成 WGS_1984_UTM_Zone_49N 投影。同时,利用 MVC (Maximum Value Composites) 合成月 NDVI 最大值, 来进一步消除云、大气和太阳高度角等因素对遥感影 像产生的影响 ${ }^{[15]}$ 。由于温带半干旱区域存在明显的季节性, 生长季与非生长季植被覆盖存在较大差异 ${ }^{[16]}$, 因此实验采用延河流域生长季 5-10 月 NDVI 的平均值表征植被覆盖的年际变化状况 ${ }^{[17]}$; (2) DEM 数据来自 中国科学数据云地理空间数据云 (http://www.gscloud.cn/), 空间分辨率为 $30 \mathrm{~m}$; (3) 土地利用数据来源于中 国科学院资源科学环境数据中心 (http://www.resdc.cn/), 空间分辨率为 $30 \mathrm{~m}$, 本文选用 2005 年和 2010 年土 地利用数据, 主要包括八类土地利用类型: 耕地、林地、园地、高覆盖草地、低覆盖草地、建设用地、水域和未利 用地, 按照 SWAT 模型自带的土地利用类型编码方式建立相对应的属性索引表, 构建土地利用数据库; (4) 土 壤数据采用寒区旱区科学数据中心 (http://westdc.westgis.ac.cn/) 提供的世界土壤数据库 ( Harmonized World Soil Database, HWSD), 其中的中国土壤数据是第二次全国土地调查南京土壤所提供的 1:100 万土壤数据, 利 
用 SPAW (Soil-Plant-Atmosphere-Water) 软件计算所需土壤参数,建立土壤数据库; (5) 水文数据来自《中华人 民共和国水文统计年鉴》的黄河流域资料,包括甘谷驿水文站 2003-2015 年逐日径流量和产沙量; (6)气象 数据来自中国气象数据共享网 (https://data. cma.cn/), 包括延河流域内及周边站点的位置信息和 19992015 年逐日降水量、最高和最低温度、相对湿度、风速数据。由于目前国家基本气象站点无太阳辐射数据, 所 以该数据由天气发生器模拟提供。为了减小空间数据带来的偏差, 本文将所有的空间数据投影变换为统一的 坐标系( WGS_1984_UTM_Zone_49N), 且栅格分辨率重采样为 $30 \mathrm{~m}$ 。

\section{2 研究方法}

\subsection{NDVI 变化特征}

NDVI 可从整体上表征植被的生长状况和覆盖变化 ${ }^{[18-19]}$, 被众多学者广泛应用 ${ }^{[20-22]}$ 。本文运用趋势线分 析法逐像元分析 2000-2015 年延河流域的 NDVI 变化趋势, 反映植被的时间演变和空间差异特征。依据趋 势线的斜率判断变量在研究时段的变化趋势, 若斜率大于 0 , 则植被覆盖呈增加趋势; 若斜率等于 0 , 则植被生 长趋于稳定; 若斜率小于 0 , 则植被覆盖呈减少趋势。斜率绝对值的大小表示研究时段植被覆盖增加或减少 的速率。计算公式如下:

$$
\theta=\frac{n \sum_{j=1}^{n} j x_{j}-\sum_{j=1}^{n} j \sum_{j=1}^{n} x_{j}}{n \sum_{j=1}^{n} j^{2}-\left(\sum_{j=1}^{n} j\right)^{2}}
$$

式中, $\theta$ 为趋势线的斜率; $n$ 为研究时段年数; $x_{j}$ 为研究时段内第 $j$ 年年际或生长季 NDVI 值。

\subsection{SWAT 模型}

美国农业部农业研究中心开发了具有很强物理机制、开源的 SWAT 分布式水文模型,其可以综合利用土 壤类型、土地利用类型及管理措施预测和模拟流域长时期内的径流、泥沙、化学元素和有机物质的迁移运动, 评估整个流域范围内的水分平衡 ${ }^{[23]}$ 。该模型广泛应用于黄土高原地区的产流产沙模拟 ${ }^{[24-25]}$, 因此,本文采用 SWAT 模型中的产沙模块, 即改进的通用水土流失方程 (Modified Universal Soil Loss Equation, MUSLE) 模拟延 河流域的土壤侵蚀量,包括实际土壤侵蚀量和潜在土壤侵蚀量。实际土壤侵蚀量指流域实际上发生的土壤侵 蚀量, 潜在土壤侵蚀量指假设流域没有地表植被覆盖与管理措施下发生的土壤侵蚀量, 二者之间的差值为土 壤保持量。计算公式如下:

$$
\Delta S=S_{q z}-S_{s j}=11.8 \cdot\left(Q_{\text {surf }} \cdot q_{\text {peak }} \cdot \text { area }_{\text {hru }}\right)^{0.56} \cdot K_{\text {usle }} \cdot P_{\text {usle }} \cdot L S_{\text {usle }} \cdot \mathrm{CFRG} \cdot\left(1-C_{\text {usle }}\right)
$$

式中, $S_{s j}$ 为模拟的实际土壤侵蚀量 $(\mathrm{t}) ; S_{q z}$ 为模拟的潜在土壤侵蚀量 $(\mathrm{t}) ; \Delta S$ 为研究区生态系统土壤保持量 $(\mathrm{t}) ; Q_{\text {surf }}$ 为地表径流 $\left(\mathrm{mm} / \mathrm{hm}^{2}\right) ; q_{\text {peak }}$ 为径流峰值 $\left(\mathrm{m}^{3} / \mathrm{s}\right)$; area $_{\text {hru }}$ 为水文响应单元 (Hydrologic Research Unit, $\mathrm{HRU})$ 的面积 $\left(\mathrm{hm}^{2}\right) ; K_{\text {usle }}$ 为土壤可蚀性因子; $C_{\text {usle }}$ 为地表植被覆盖与管理因子, 当无植被覆盖与管理因子的影 响时, 设 $C_{\text {usle }}=1 ; P_{\text {usle }}$ 为水土保持措施因子; $L S_{\text {usle }}$ 为地形因子, 包括坡长因子 $L$ 和坡度因子 $S ;$ CFRG 为直径大 于 $2 \mathrm{~mm}$ 的粗碎块因子。

采用德克萨斯农业大学提供的 SWAT - Calibration and Uncertainty Programs (SWAT-CUP) 软件中的 Sequential Uncertainty Fitting (SUFI-2) 方法对 SWAT 模型进行敏感性参数分析、率定和验证。使用决定系数 (Coefficient of determination, $R^{2}$ ) 和纳什效率系数 (Nash-Sutcliffe efficiency coefficient, NSE) 作为评价 SWAT 模型模拟精度的指标。 $R^{2}$ 可评价模拟值与实测值变化趋势的一致性, NSE 可反映模拟值与实测值之间的拟 合程度。一般来说, 当 $R^{2}>0.6$, 且 NSE $>0.5$ 时, 即可认为 SWAT 模型模拟取得显著性效果 ${ }^{[26]}$ 。评价指标的表 达式如下:

$$
R^{2}=\frac{\left[\sum_{i=1}^{n}\left(Q_{o i}-Q_{o}\right)\left(Q_{m i}-Q_{m}\right)\right]^{2}}{\sum_{i=1}^{n}\left(Q_{o i}-Q_{o}\right)^{2} \sum_{i=1}^{n}\left(Q_{m i}-Q_{m}\right)^{2}}
$$




$$
\mathrm{NSE}=1-\frac{\sum_{i=1}^{n}\left(Q_{m i}-Q_{o i}\right)^{2}}{\sum_{i=1}^{n}\left(Q_{o i}-Q_{o}\right)^{2}}
$$

式中, $Q_{m i}$ 为模拟值; $Q_{o i}$ 为实测值; $Q_{o}$ 为实测均值 $; Q_{m}$ 为模拟均值。

通过基础数据的准备, 构建数据库, 借助 ArcSWAT2012 版本软件建立延河流域的 SWAT 模型。首先是子 流域的划分: 基于 DEM 数据生成河网,通过设定阈值(形成子流域的最小给水面积) 为 $10000 \mathrm{hm}^{2}$ 重新划分河 网, 并设置流域总出水口, 流域划分为 47 个子流域; 其次划分 $\mathrm{HRU}$ : 通过叠加土地利用数据、土壤数据和坡度 数据, 获得各个子流域中具有相同土地利用类型、土壤类型和坡度的 1987 个 HRUs; 最后将气象数据等导人模 型, 重新读取基础数据库, 运行 SWAT 模型, 实现对延河流域 1999-2015 年径流量和产沙量的模拟。以 1999-2002 年作为预热期,再分别以 2003-2008 年和 2009-2015 年作为率定期和验证期,并依据甘谷驿水文站 实测数据进行参数率定和验证。由于延河流域的地形、土壤等基础数据长时间内几乎不变, 而流域内的土地利 用状况不断变化。为提高 SWAT 模型的精度,本文将 1999-2008 年(预热期+率定期) 作为整体,运用 2005 年的 土地利用数据驱动 SWAT 模型; 2009-2015 年(验证期) 选用 2010 年的土地利用数据驱动 SWAT 模型。经验证, 本文构建的延河流域 SWAT 模型率定和验证结果均达到模型要求(如图 2), 可用于研究区的水文模拟。
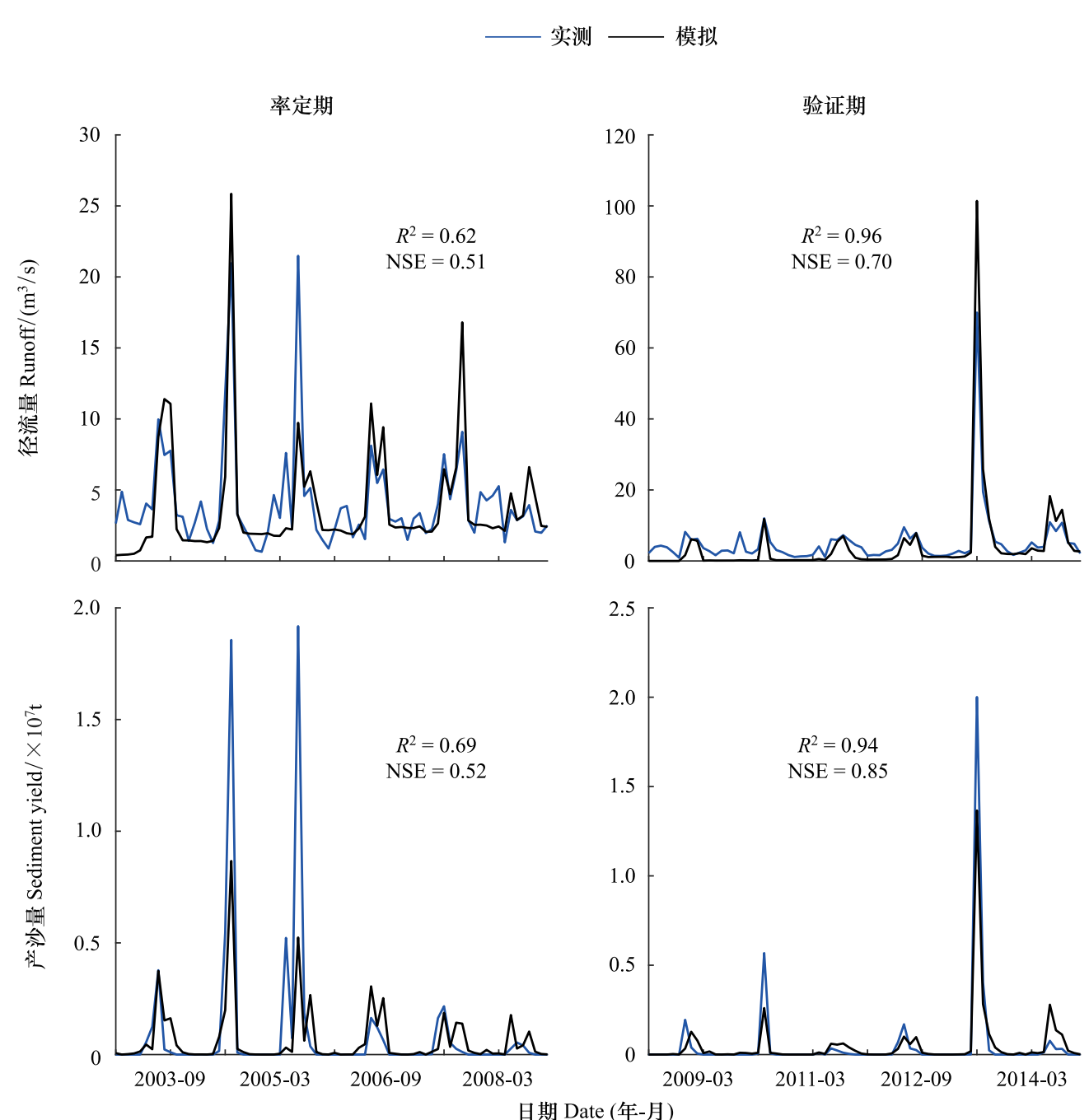

图 2 延河流域甘谷驿水文站径流-产沙实测值与模拟值对比图

Fig.2 Comparison of observed and simulated values of runoff-sediment yield in Ganguyi hydrological station of Yanhe Watershed 


\section{3 生态系统土壤保持服务价值评估}

采用市场价值法、机会成本法、恢复费用法和影子工程法等生态系统服务价值核算方法,依据每个 HRU 上的生态系统土壤保持量, 从保持土壤肥力、减少土地废弃和减轻泥沙淤积 (3 个指标) 方面定量估算土壤保 持服务价值,最后汇总计算流域总价值量,阐明植被恢复的生态效益。

$$
\begin{aligned}
& E_{1}=\Delta S \times B_{i} \times C_{i} \times D_{i} \\
& E_{2}=\Delta S \times \frac{D_{1}}{p \times h} \\
& E_{3}=0.24 \times \Delta S \times \frac{D_{2}}{p} \\
& E=E_{1}+E_{2}+E_{3}
\end{aligned}
$$

式中, $E$ 为生态系统土壤保持服务价值 (元) $; E_{1}$ 为保持土壤肥力价值 (元) $; E_{2}$ 为减少土地废弃价值 $\left(\right.$ 元) $; E_{3}$ 为减轻泥沙淤积价值 (元); $\Delta S$ 为研究区生态系统土壤保持量 $(\mathrm{t}) ; B_{i}$ 为土壤中氮、磷、钾及有机质的平均含 量, 分别为 $0.17 \% 、 0.06 \% 、 1.40 \% 、 0.90 \%{ }^{[27]}$; $C_{i}$ 为土壤中的氮、磷、钾及有机质折算成相应肥料(尿素、过磷酸 钙和氯化钾) 及碳比率的系数, 分别为 $2.164 、 4.065 、 1.923 、 0.5^{[28]} ; D_{i}$ 为化肥的市场价格 (元/ $\mathrm{t}$ ), 依据全国肥料 的平均售价, 分别为 $1825 、 522 、 1948 、 550$ 元 $/ \mathrm{t} ; D_{1}$ 为单位面积土地的机会成本, 取值为 $2.35 \times 10^{5}$ 元 $\mathrm{km}^{-2}$ $\mathrm{a}^{-1[27]} ; p$ 为单位土壤体积质量分数, 取值为 $1.20 \mathrm{t} / \mathrm{m}^{3} ; h$ 为土壤厚度, 江忠善、郑粉莉等 ${ }^{[29-30]}$ 提出的黄土高原 地区平均土壤厚度为 $0.2 \mathrm{~m}$; 依据中国主要河流泥沙运动规律, 土壤流失泥沙淤积在河道、湖泊、水库中的系数 取 $0.24^{[31]} ; D_{2}$ 为建设水库工程的费用, 取 5.714 元 $/ \mathrm{m}^{3[27]}$ 。

\section{3 结果与分析}

3.1 NDVI 时空变化特征

\subsection{1 年际 NDVI 时空变化}

从图 3 可以看出,2000-2015 年 NDVI 均值表现出 递增的趋势,增速达到 $0.0245 / 10 \mathrm{a}$ 。其中, NDVI 平均值 由 2000 年的 0.514 增加到 2014 年的 0.553 , 其增长率达 到 $7.05 \%$, 主要是由于退耕还林 (草) 工程的实施, 在政 策因素和人为因素的影响下, 延河流域大量耕地实现还 林还草, 植被覆盖状况逐渐改善。为更好评价延河流域 植被恢复状况,分析该流域 2000-2015 年 NDVI 时空 变化趋势。经统计相关系数显著性检验, 参考岳本江 等 ${ }^{[32]}$ 对延河流域 NDVI 变化趋势分级标准理论并结合 本文研究对象实际情况, 将该流域的 NDVI 变化情况划 分为明显退化 $(\theta \leqslant-0.007)$ 、退化 $(-0.007<\theta \leqslant$

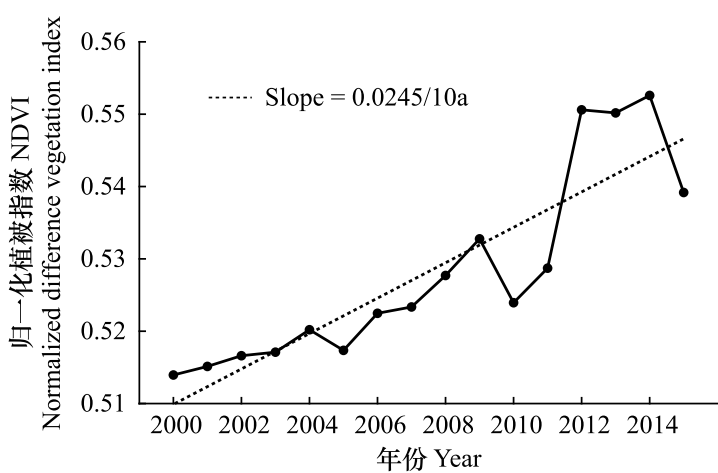

图 $32000-2015$ 年延河流域 NDVI 变化趋势

Fig.3 Inter-annual variations of NDVI in Yanhe Watershed from 2000 to 2015 $-0.001)$ 、基本不变 $(-0.001<\theta \leqslant 0.001)$ 、改善 $(0.001<\theta<$ $0.004)$ 和明显改善 $(\theta \geqslant 0.004) 5$ 个等级。

由图 4 可知,绿色区域的 NDVI 呈现出增加的趋势,其中 $84 \%$ 的区域改善,9.6\%的区域明显改善,主要位 于流域上游和下游。由于流域上游地势陡峭, 坡度大于 $25^{\circ}$ 的陡坡占 $70 \%$ 以上 ${ }^{[6]}$, 而退耕还林(草) 工程对于 坡度大于 $25^{\circ}$ 的坡耕地实现了全部还林, 导致植被覆盖变化大, 植被恢复好; 而下游地区地势平缓, 土壤肥沃, 农业活动频繁, 土地缺乏植被保护, 对该地区平缓的坡耕地进行退耕还草, 植被得到保护, 使得植被覆盖逐渐 增大。还有 $6.1 \%$ 的区域 NDVI 变化趋势基本不变, 主要位于流域中游, 这是因为延安市以南地区梢林广布, 植被生长状况好造成的结果。流域仅有 $0.3 \%$ 的区域 NDVI 出现减少的趋势, 主要分布于延安市新区, 由于城 
市化使得植被退化显著。

\subsection{2 生长季 NDVI 时空变化}

生长季 NDVI 时间变化分析。本文把一年中植被 开始返青到落叶的时期作为生长季 ${ }^{[33-34]}$, 根据延河流 域的物候特征, 其生长季从 5 月初至 10 月底。由于 MODIS-NDVI 的影像为半月合成产品, 把 NDVI 均值分 为上、下半月, 可以在时间上更细致的表达植被覆盖的 变化情况。如图 5 所示, 以时间为横轴 (刻度为半月), 以 NDVI 均值为纵轴, 用回归法生成拟合曲线, 即 NDVI 变化趋势线, 其斜率反映变化率。经统计 2000-2015 年生长季各月 (5-10月), 时间与 NDVI 的相关系数大 于 $0.6(P<0.01), 2000-2015$ 年生长季 NDVI 变化呈现 出逐年增加的总趋势, 但不同月份的增加程度不同。其 中每年 8 月的 NDVI 值最大, 每年 6 月的 NDVI 增长速

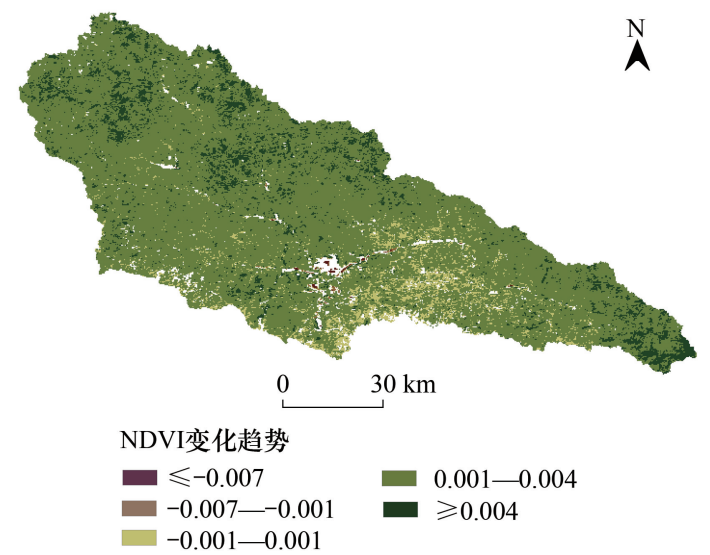

图 $42000-2015$ 年延河流域 NDVI 年际变化趋势空间分布图 Fig.4 Inter-annual spatial variation of NDVI in Yanhe Watershed from 2000 to 2015 率最快 (拟合曲线斜率最大), 主要原因是流域气候条 件和植被物候的季节差异 ${ }^{[35]}$ 。而一年中 NDVI 随物候变化, 5-8 月 NDVI 值逐渐增大, 9-10 月 NDVI 值逐渐 减少。

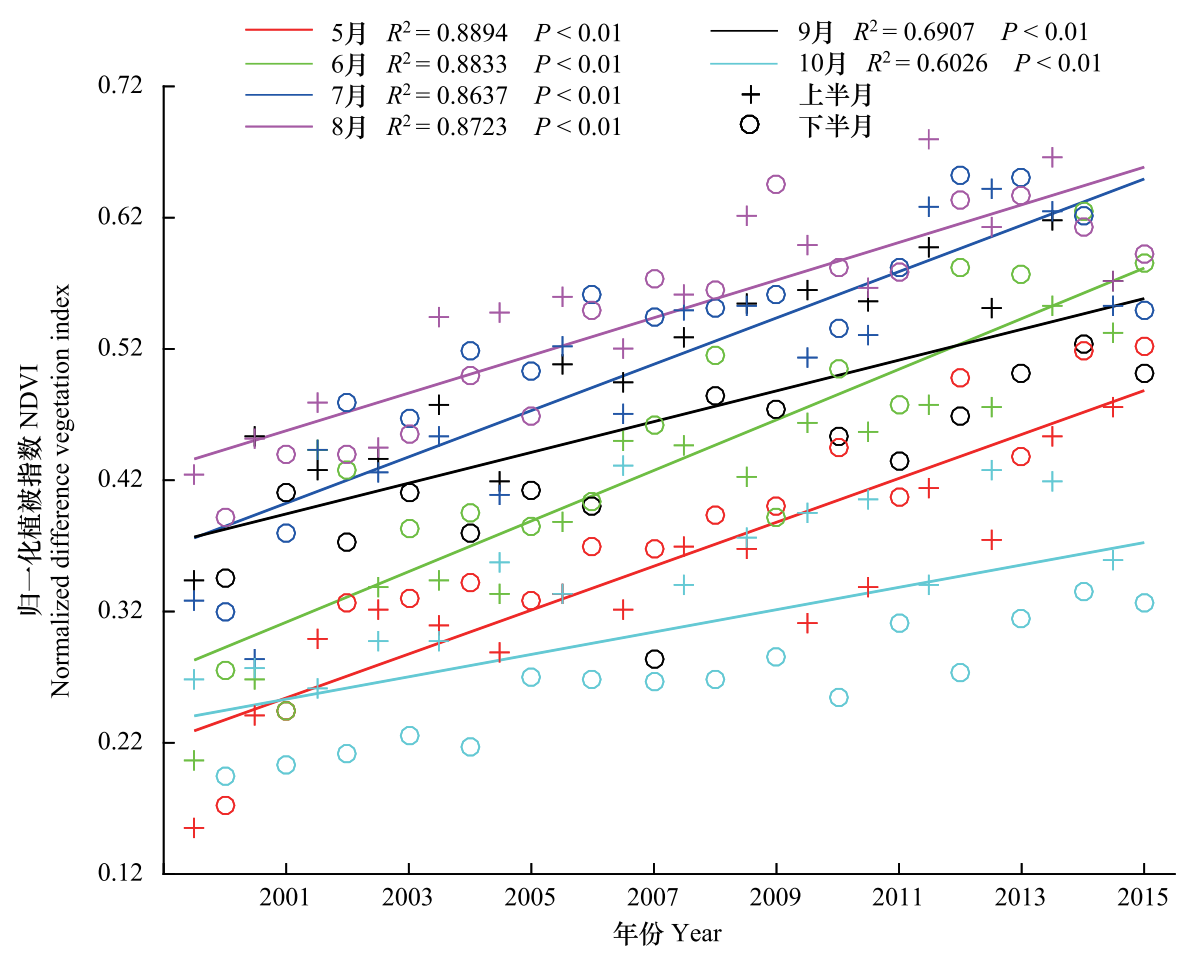

图 $52000-2015$ 年延河流域生长季 NDVI 月均值趋势图

Fig.5 Monthly variations of growing season NDVI in Yanhe Watershed from 2000 to 2015

生长季 NDVI 空间变化分析。如图 6 所示, 2000-2015 年各月 NDVI 变化的空间差异显著, 主要由于植 被在一年内经历开始返青 (生长季始期) 到落叶 (生长季末期) 的过程, 植被进人生长季始期和生长季末期的 面积比例均为先增加后减少 ${ }^{[33-34]}$ 。依据上文 NDVI 变化趋势分级标准, 其中生长季始期 (5 月) NDVI 增加的 区域主要分布在流域中游, 该地区位于延安市城区附近, 受人类活动影响较大, 植被生长较上游和下游更好; 
6 月NDVI 增加的区域主要位于下游, 由于下游地区退耕还林(草)工程实施效果显著,使得下游植被状况逐渐 改善; 7 月 NDVI 增加的区域占 $97.8 \%$,全流域植被长势较好; 8 月 NDVI 增加的区域主要位于上游和下游, 中 游植被生长状况趋于稳定, 这与图 5 中 8 月 NDVI 值最大形成呼应, 全流域植被生长状况最好; 9 月全流域 NDVI 增加趋缓,植被进入生长季末期; 10 月 NDVI 变化趋势呈增加的区域主要位于上游,退耕还林(草)工程 实施中流域上游的坡耕地还林的效果显著。

总体上看,该流域 NDVI 时空变化特征为 2000-2015 年生长季各月 NDVI 值及 NDVI 增长速率不同,表 现在空间上,流域上中下游植被变化呈现出不同的趋势,这与植被类型、地势条件、气候条件、人类活动等因素 相关。
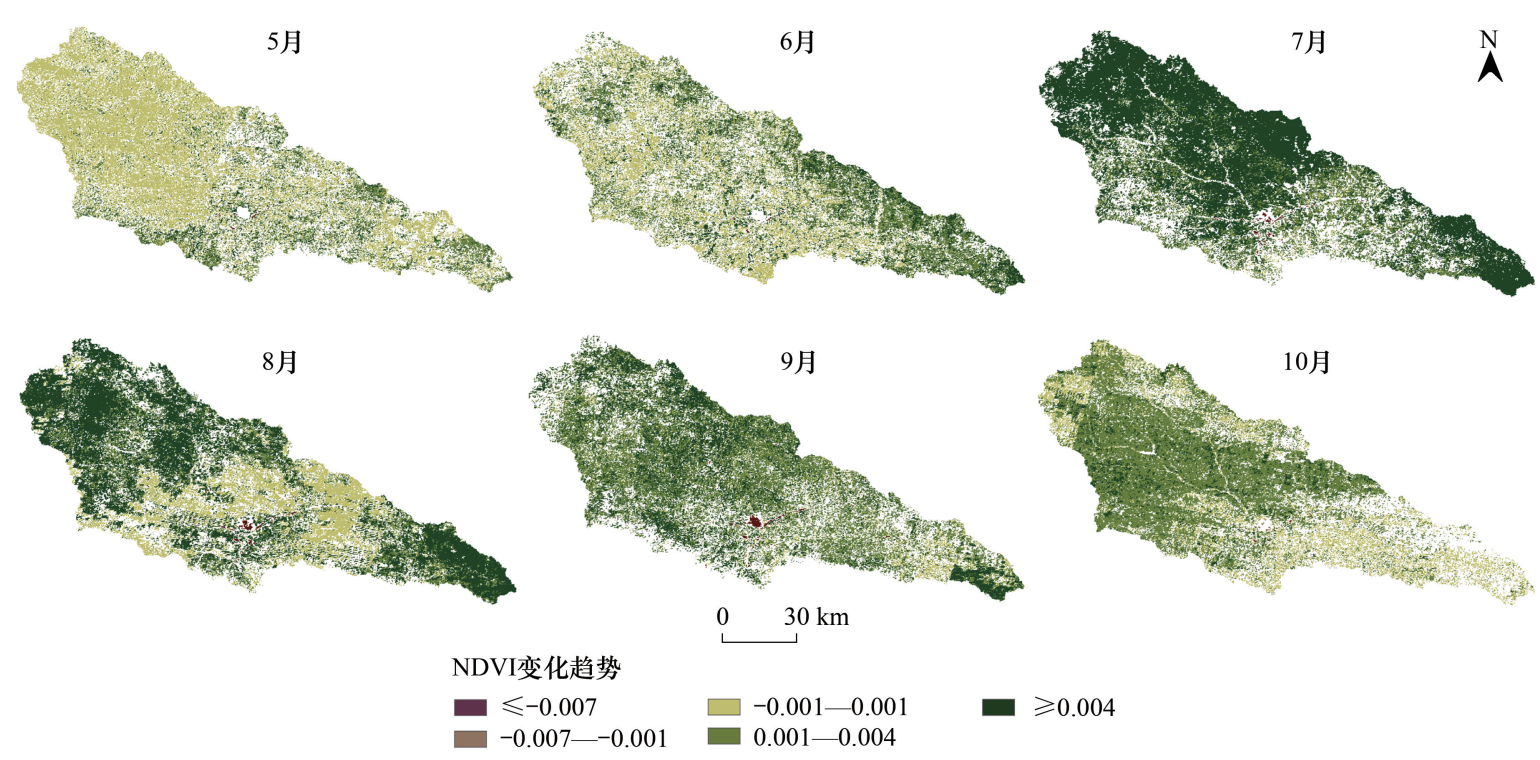

ᄂ $\quad 30 \mathrm{~km}$

$$
\square=-0.007 \quad 0.001-0.001 \quad \square \geqslant 0.004
$$

图 $62000-2015$ 年延河流域生长季 NDVI 月际变化趋势空间分布图

Fig.6 Monthly spatial variations of growing season NDVI in Yanhe Watershed from 2000 to 2015

3.2 植被覆盖对土壤保持服务的作用

为探究植被覆盖措施对土壤侵蚀的影响,本文借助 SWAT 水文模型, 以植被覆盖措施作为模型的变量, 以 HRU 为研究单元, 定量模拟土壤侵蚀量, 以此说明植被 覆盖变化对流域土壤保持的积极作用。从图 7 可以看 出, 在 HRUs 尺度上, 2000-2015 年年均实际和潜在土 壤侵蚀模数的拟合曲线整体上呈减少趋势,其中多年平 均实际和潜在的土壤侵蚀模数为 $31783 \mathrm{t} \mathrm{km}^{-2} \mathrm{a}^{-1}$ 和 $624015 \mathrm{t} \mathrm{km}^{-2} \mathrm{a}^{-1}$, 主要是因为流域的土壤类型多为黄土 母质上发育的黄绵土, 土壤质地均一, 土质疏松,抗侵蚀 能力差 ${ }^{[36]}$,在没有植被覆盖措施下,土壤极易发生侵 蚀,且侵蚀模数大。由此定性说明植被覆盖对土壤侵蚀 具有强大的抑制作用。

如何定量探究植被覆盖发挥的效果是一个值得研究的问题。基于此,本文以 2000 年土壤保持量为基准, 计算 2001-2014 年逐年土壤保持增量,从定量的角度深究植被恢复带来土壤保持量的变化特征。从表 1 可知, 2001-2014 年土壤保持量均存在不同程度的增加。植被覆盖抑制土壤侵蚀, 土壤得到有效保持, 土壤保持又促 进植被生长, 从而形成良性循环, 不断改善生态环境。因此, 在今后的生态恢复中要注重植被覆盖措施。 
表 $12001-2014$ 年延河流域土壤保持量增益表

Table 1 Soil conservation increment in Yanhe Watershed from 2001 to 2014

\begin{tabular}{cc||cc||cc}
\hline $\begin{array}{c}\text { 年份 } \\
\text { Year }\end{array}$ & $\begin{array}{c}\text { 土壤保持增量/ } \\
\text { Soil conservation increment }\end{array}$ & $\begin{array}{c}\text { 年份 } \\
\text { Year }\end{array}$ & $\begin{array}{c}\text { 土壤保持增量/ } \\
\text { Soil conservation increment }\end{array}$ & $\begin{array}{c}\text { 年份 } \\
\text { Year }\end{array}$ & $\begin{array}{c}\text { 土壤保持增量/t } \\
\text { Soil conservation increment }\end{array}$ \\
\cline { 2 - 4 } 2001 & 358740 & 2006 & 1216522 & 2011 & 43671 \\
2002 & 1640335 & 2007 & 233117 & 2012 & 341383 \\
2003 & 3826615 & 2008 & 26835 & 2013 & 57198108 \\
2004 & 8728359 & 2009 & 2461743 & 2014 & 8379022 \\
2005 & 1112826 & 2010 & 3344784 & & \\
\hline
\end{tabular}

植被覆盖措施是减少土壤侵蚀的重要因素之一。从不同植被覆盖度的角度分析土壤保持量的变化是极 具价值的。参照宋敏敏等 ${ }^{[37]}$ 在延河流域已有的研究经验, 采用自然间断点分级法, 将 NDVI 分为低覆盖 (0$0.3)$ 、中低覆盖 $(0.3-0.45)$ 、中覆盖 $(0.45-0.6)$ 、中高覆盖 $(0.6-0.75)$ 、高覆盖 $(0.75-1) 5$ 个等级。经统计， 2000-2015 年延河流域的植被覆盖情况为: 低覆盖占 $0.26 \%$,中低覆盖占 $15.8 \%$,中覆盖占 $66.43 \%$,中高覆盖 占 $17.05 \%$, 高覆盖占 $0.46 \%$, 说明延河流域植被主要以中覆盖为主。为更明确土壤保持量的变化, 标准化多 年(2000-2015) 平均土壤保持量,参照邓伟等 ${ }^{[38]}$ 的研究,采用等间隔分级法,将标准化后的土壤保持量划分 为低 $(0-0.2)$ 、较低 $(0.2-0.4)$ 、中 $(0.4-0.6)$ 、较高 $(0.6-0.8)$ 、高 $(0.8-1) 5$ 个等级。延河流域各等级土壤 保持量如下:低保持占 $75.77 \%$, 较低保持占 $13.64 \%$, 中保持占 $6.72 \%$,较高保持占 3.17 , 高保持占 $0.7 \%$,表明 该流域土壤保持量以低保持为主。

运用叠加分析法,研究植被覆盖对土壤保持量的影 响。从图 8 可以看出,流域植被覆盖变化引起土壤保持 量的变化特征明显。低覆盖下土壤保持量几乎为 0 ,由 于植被覆盖度小于 0.3 ,地表景观为裸岩、裸土和稀疏植 被 ${ }^{[39]}$, 土壤侵蚀严重; 中低覆盖下,存在低、较低、中和 较高土壤保持, 几乎没有高保持, 反映出中低植被覆盖 条件下, 生态系统土壤保持功能仍有限; 而中覆盖条件 下, 高保持面积占比最大, 为 $85.35 \%$, 反映出生态系统 土壤保持功能强, 主要原因是对先前坡度大于 $25^{\circ}$ 、农 业活动频繁和矿区等地区还草还林力度大, 植被恢复显 著、覆盖度高,所以土壤侵蚀量大幅减少; 流域高覆盖区 面积占比最小, 仅不到 $1 \%$, 因此土壤保持功能强但总 量小。因此,今后水土保持工作要注意对各个等级植被 覆盖采取不同的措施: 低覆盖区重点治理, 中低、中和中

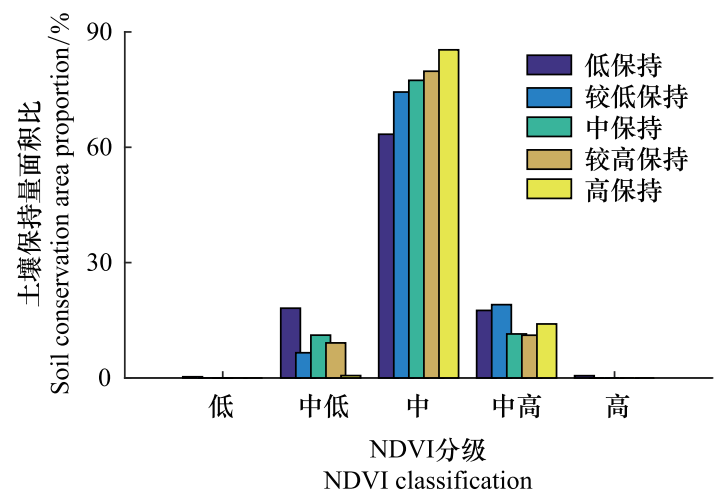

图 $82000-2015$ 年延河流域不同植被覆盖下的土壤保持量面积 比较

Fig.8 Comparison of soil conservation area under different vegetation cover in Yanhe Watershed from 2000 to 2015 高覆盖区预防保护,着重扩大高覆盖区。

3.3 生态系统土壤保持服务价值时空分布

\subsection{1 时间尺度变化}

土壤保持服务作为一项重要的生态系统调节服务,在防止土壤侵蚀,减少泥沙等方面发挥重要的作 用 ${ }^{[40-41]}$ 。为定量评估植被恢复所带来的生态系统土壤保持服务价值,本文通过公式(5-8) 计算土壤保持服 务价值并分析其时空分布特征, 探究植被恢复对土壤保持服务的增益效果。

从图 9 可以看出, 时间尺度上, HRUs 年均土壤保持服务价值随时间波动, 主要原因是 2000-2015 年的降 水量和降水强度不同, 导致土壤侵蚀程度不同。其中 2013 年土壤保持服务价值达到多年最大值, 因为 2013 年延河流域遭遇有气象记录以来的强降水 ${ }^{[42]}$, 该年降水量约为 $790 \mathrm{~mm}$, 是 $2000-2015$ 年降水量的最大值。 总体看, 生长季 HRUs 月均土壤保持服务价值在年内呈单峰型变化, 峰值在 7 月, 主要是因为流域多年以来年 
内降水量也呈单峰型变化, 7 月降水量约为 $111 \mathrm{~mm}$, 达到年内最大值, 且以阵雨或暴雨为主, 局部地区出现暴 雨的情况较多, 暴雨强度也大。本文土壤保持服务价值随时间的变化特征与张乐涛等 ${ }^{[43]}$ 研究产沙量变化情 况相吻合。黄土高原地区几乎所有的土壤侵蚀量都发生在雨季, 且随着降水量的增加土壤保持量增加, 由此 表明土壤保持量在时间尺度上受降水因素的影响, 产生的生态系统土壤保持服务价值也随之波动。在多雨季 节, 适宜的温度和降水促进了植被的生长, 当 NDVI 达到峰值时, 产沙量迅速下降, 土壤保持量快速增加。因 此,植被覆盖是减少黄土高原地区水土流失的主要因素。

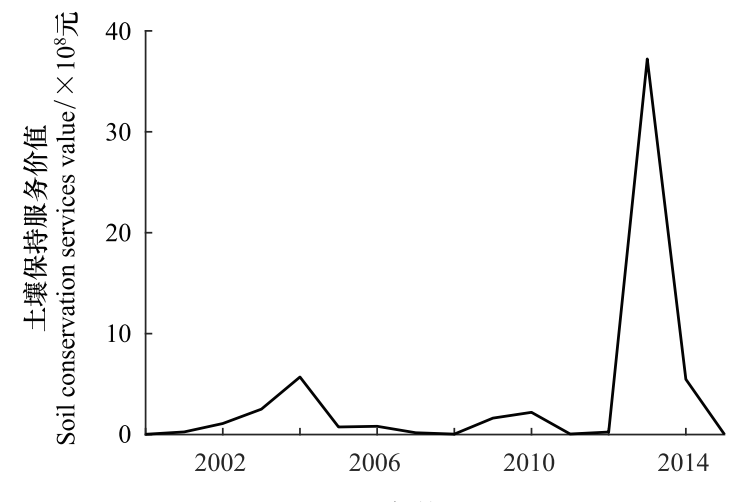

年份 Year

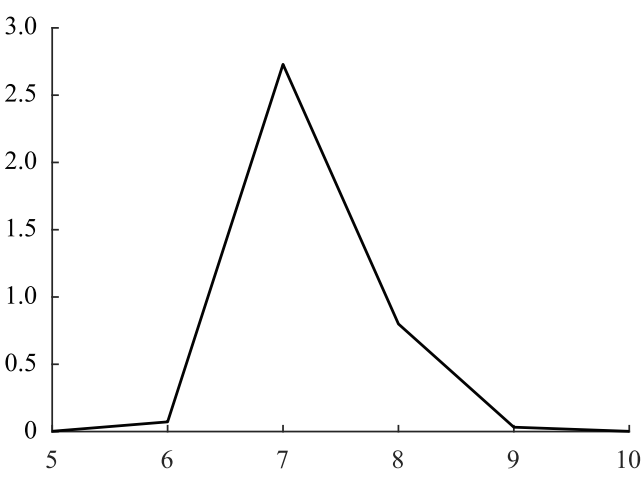

月份 Month

图 $92000-2015$ 年延河流域年际年内 HRUs 土壤保持服务价值图

Fig.9 HRUs soil conservation services value (Inter-annual and growing season) in Yanhe Watershed from 2000 to2015

2000-2015 年 HRUs 年均土壤保持服务价值为 $3.64 \times 10^{8}$ 元, 生长季月均土壤保持服务价值为 $6.06 \times 10^{7}$ 元。从表 2 和表 3 可以看出, 年际和年内保持土壤肥力价值 $E_{1}$ 、减少土地废弃价值 $E_{2}$ 和减轻泥沙淤积价值 $E_{3}$ 对土壤保持服务价值的贡献不同,其中 $E_{1}$ 占 $96.7 \%, E_{2}$ 占 $1.5 \%, E_{3}$ 占 $1.8 \%$,表明 2000-2015 年延河流域 生态系统土壤保持服务价值以保持土壤肥力价值为主。

总体上看, 2000-2015 年延河流域土壤保持服务价值呈波动增长的态势,生态系统土壤保持服务增益明 显, 从 2000 年仅为 $2.63 \times 10^{6}$ 元, 至 2014 年已增长为 $5.48 \times 10^{8}$ 元, 翻了一番。

表 $22000-2015$ 年延河流域年际 HRUs 土壤保持服务价值

Table 2 HRUs soil conservation services value in Yanhe Watershed from 2000 to 2015

\begin{tabular}{cccc}
\hline 年份 & 保持土壤肥力价 $E_{1} /\left(\times 10^{5}\right.$ 元 $)$ & $\begin{array}{c}\text { 减少土地废弃价值 } E_{2} /\left(\times 10^{3} \text { 元 }\right) \\
\text { Reduce the value of land abandonment }\end{array}$ & $\begin{array}{c}\text { 减轻泥沙淤积价值 } E_{3} /\left(\times 10^{3} \text { 元 }\right) \\
\text { Reduce the value of sedimentation }\end{array}$ \\
\hline 2000 & Maintain the value of soil fertility & 40 & 46 \\
2001 & 25 & 390 & 460 \\
2002 & 1060 & 1650 & 1900 \\
2003 & 2430 & 3790 & 4400 \\
2004 & 5520 & 8590 & 10000 \\
2005 & 730 & 1130 & 1300 \\
2006 & 790 & 1230 & 1400 \\
2007 & 170 & 270 & 310 \\
2008 & 42 & 66 & 77 \\
2009 & 1570 & 2450 & 2900 \\
2010 & 2130 & 3310 & 3900 \\
2011 & 53 & 82 & 96 \\
2012 & 240 & 370 & 440 \\
2013 & 36010 & 56050 & 65000 \\
2014 & 5300 & 8240 & 9600 \\
2015 & 17 & 27 & 31 \\
\hline
\end{tabular}


表 3 生长季 HRUs 多年 $(2000-2015)$ 平均土壤保持服务价值

Table 3 Multi-year (2000-2015) average soil conservation services value of HRUs during growing season

\begin{tabular}{cccc}
\hline $\begin{array}{c}\text { 月份 } \\
\text { Month }\end{array}$ & $\begin{array}{c}\text { 保持土壤肥力价值 } E_{1} /\left(\times 10^{2} \text { 元 }\right) \\
\text { Maintain the value of soil fertility }\end{array}$ & $\begin{array}{c}\text { 减少土地废弃价值 } E_{2} /\left(\times 10^{2} \text { 元 }\right) \\
\text { Reduce the value of land abandonment }\end{array}$ & $\begin{array}{c}\text { 减轻泥沙淤积价值 } E_{3} /\left(\times 10^{2} \text { 元 }\right) \\
\text { Reduce the value of sedimentation }\end{array}$ \\
\hline 5 & 20 & 32 & 37 \\
6 & 700 & 1084 & 47960 \\
7 & 264000 & 41095 & 14054 \\
8 & 7740 & 12042 & 570 \\
9 & 310 & 490 & 29 \\
\hline
\end{tabular}

\subsection{2 空间尺度变化}

本文重点分析退耕还林 (草)工程实施以后, 延河流域生态系统土壤保持服务价值的空间差异,希望能为 该地区今后退耕还林(草)工程实施的方向提供参考依据。从图 10 可以看出,2000 年和 2014 年流域的土壤 保持服务价值空间差异大。2000 年流域的土壤保持服务价值分布多集中在上游地区,主要是因为延河流域 地势西北高、东南低,西北部的坡度大于 $25^{\circ}$ 的坡耕地多,退耕还林(草) 工程实施初期对该地区的还林力度 大;2014 年土壤保持服务价值在流域内趋于均匀分布的态势, 因为退耕还林(草)工程实施以来, 全流域植被 恢复显著,全面提升了生态系统土壤保持服务,进而带来显著生态效益。流域年均土壤保持服务价值在下游 地区最高, 上游次之, 中游最低, 其原因为:下游残塬平梁沟壑区地势平坦, 土壤肥沃, 农业活动频繁, 先前土地 缺乏植被保护导致水土流失严重,通过退耕还草, 土壤保持量大幅提升; 上游低山地区植被生长环境差, 通过 退耕还林、园林绿化、水保工程措施等, 使得土壤侵蚀减弱, 相较于中游, 土壤保持服务价值更高; 中游梁峁丘 陵沟壑区侵蚀严重, 并且延安市宝塔区人口较多, 人类活动频繁, 城市建设导致不透水面不断增加, 因此土壤 保持服务价值低。今后水保工作要注意对流域上中下游采取不同措施: 上游限制土地开发, 以生态恢复为重; 中游生态与建设并重, 加强土地规划与保护; 下游因地制宜, 合理开展高附加值农业活动提高土地生产效率, 主要种植果树、牧草等植被覆盖度较高的作物,尝试免耕法等保护性耕作方式。

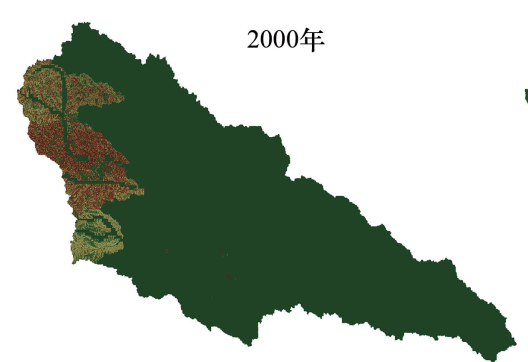

土壤保持价值/元

高: 215072

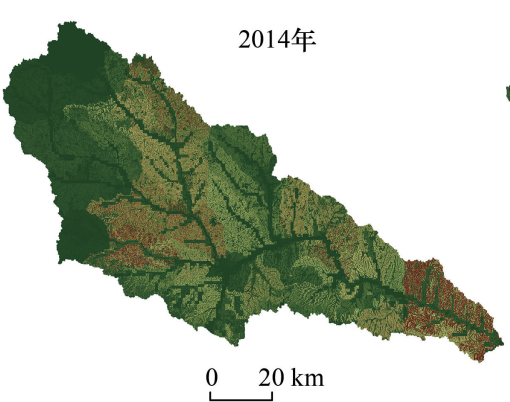

土塤保持价值/元

高: 15616400

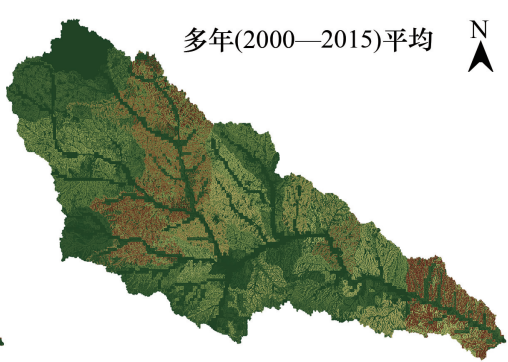

土壤保持价值/元

高: 8395440 低: 0

图 10 延河流域土壤保持服务价值空间分布图

Fig.10 Spatial distribution of soil conservation services value in Yanhe Watershed

\section{4 结论}

本文以黄土高原延河流域为研究对象, 运用 MODIS-NDVI 数据探究 2000-2015 年研究区植被恢复的时 空变化特征, 同时基于 SWAT 模型揭示植被恢复对抑制土壤侵蚀、提高土壤保持的作用,并定量评价生态系统 土壤保持服务价值增益效果。主要得出以下结论: 
(1) 通过分析 2000-2015 年延河流域年际和生长季 NDVI 的时空变化特征,得出该流域植被覆盖整体上 处于增加态势,退耕还林(草)工程实施效果显著,持续向好。但是上中下游存在空间差异, 流域上游植被覆 盖变化大、植被恢复好; 下游地区植被覆盖逐渐转好; 而流域中游, 出现城市化快速增长区植被退化问题。因 此, 在黄土高原生态脆弱区, 城市化发展要立足于生态可持续, 节约高效利用土地资源, 合理规划建设用地, 为 生态建设留足余地。

(2) 通过定量分析,探明植被恢复对抑制土壤侵蚀的作用十分显著。从退耕还林(草)工程实施以来,随 着植被覆盖度增加, 在 HRUs 尺度上年均实际土壤侵蚀模数处于逐年递减的态势, 说明植被恢复措施能够有 效抑制土壤侵蚀, 促进生态系统土壤保持量增益明显。而总体上, 延河流域植被主要以中覆盖为主, 流域土壤 保持量以低保持为主。通过运用 GIS 叠加分析法, 研究植被覆盖对土壤保持量的影响, 表明植被低覆盖条件 下生态系统土壤保持量几乎为 0 ; 植被中低覆盖条件下,生态系统土壤保持功能仍有限; 而中覆盖条件下,土 壤保持功能较强; 植被高覆盖区所占面积最小,仅不到 $1 \%$, 因此植被高覆盖区的生态系统土壤保持功能虽然 强, 但是对流域土壤保持总量的贡献很小。综上所述,今后的水土保持工作应该注重能够有效提高植被覆盖 度的生态恢复措施, 要注意对低覆盖区重点治理,中低、中和中高覆盖区预防保护,着重扩大高覆盖区。

(3) 实施退耕还林 (草) 工程带来了巨大的生态系统土壤保持服务价值增益, 从 2000 年至 2014 年翻了一 番, 流域年均 $(2000-2015)$ 生态系统土壤保持服务价值为 $3.64 \times 10^{8}$ 元, 生长季月均土壤保持服务价值为 $6.06 \times 10^{7}$ 元, 而且土壤保持服务价值以保持土壤肥力价值为主。流域生态系统土壤保持服务价值时空分布 特征也有规律可循。时间尺度上,土壤保持服务价值受降水因素影响而波动变化; 月均土壤保持服务价值在 年内一般呈单峰型变化, 峰值在 7 月,与降水的单峰型变化相一致。空间尺度上,上中下游土壤保持服务价值 的空间差异大, 今后防治水土流失工作要注意对流域上中下游因地制宜, 采取不同措施: 上游改善生态, 中游 加强保护, 下游科学耕作。

\section{5 讨论}

(1) 当前土壤侵蚀的定量化模拟存在一定困难。土壤侵蚀是影响植被发育并受植被反作用的一种生态 应力 ${ }^{[44-45]}$ 。大多数研究 ${ }^{[46-49]}$ 土壤侵蚀采用的模型一般是美国通用水土流失方程 (Universal Soil Loss Equation, USLE), 但该模型是经验模型缺乏土壤侵蚀机理,在实际应用中不能详细描述土壤侵蚀的物理过 程。为此基于物理过程的水蚀预报模型应运而生,例如美国农业部研发了 WEPP (Water Erosion Prediction Project) 模型, 该模型几乎涉及与土壤侵蚀相关的所有过程 ${ }^{[50-51]}$, 然而这类模型存在参数众多、所需数据难以 获取等缺点, 推广应用很困难。因此,本文选择目前最流行的 SWAT 分布式水文模型。SWAT 模型采用改进 的通用水土流失方程 MUSLE 模拟基于 HRU 的土壤侵蚀量, MUSLE 中地表径流、径流峰值、土壤可蚀性等因 子的计算方法较为科学,使模型具有了一定的物理机制。

(2) 本文基于两期土地利用数据构建 SWAT 模型, 并将 HRU 作为研究单元细化了水文模拟过程。为提 高模型模拟精度, 本文在构建 SWAT 模型时基于土地利用数据、土壤数据和坡度数据将子流域划分成 HRUs 的离散集合, 把 HRU 作为研究单元, 每一个分布式地理参数(如土壤导水率、土壤可蚀性等) 都可以针对每个 HRU 进行定义,从而细化了水文过程。另一方面, 目前多数研究在借助 SWAT 模型模拟长时间序列的水文状 况时,将一期土地利用数据作为输人数据源。由于土地利用数据代表流域下垫面的状况,而下垫面对模拟水 文过程具有重要的意义,尤其是退耕还林 (草)工程实施后, 土地利用变化大, 长时间序列的研究则更需要考 虑土地利用数据的真实性。因此, 本文采用 2005 年和 2010 年两期土地利用数据作为输人数据源, 有利于提 高模型模拟的准确性。

(3) 植被动态对土壤侵蚀的影响是一个不可忽视的问题, 尚需要进一步研究。本文定量研究植被恢复的 生态系统服务价值增益问题,但植被恢复是一个长期动态的过程,如何实现基于植被动态模拟水文过程尚需 要进一步研究。MODIS 遥感数据产品 MOD13Q1 具有免费性、连续性、长时间序列等优势, 而 SWAT 模型具有 
开源性的特点,为植被动态变化的生态水文效应研究提供了必要条件。将 NDVI 数据引人 SWAT 模型实现植 被动态变化条件下的水文过程模拟,是今后研究的重难点。

(4)本文的研究结论认为退耕还林(草)工程因地制宜,将不良耕地转换为林地或草地,实现植被恢复显 著,使生态系统土壤保持服务价值增益显著。这与众多学者研究提出的实施退耕还林(草)工程以来黄土高 原水土流失减少,生态环境改善,生态系统服务价值增强的观点一致。

本文存在的不足之处: (1) 假设研究时段地形未发生变化的问题。本文将 DEM 数据和土壤数据作为长 期不变的数据源输人 SWAT 模型, 但实际上地形一直处于微小的变化,这种变化宏观遥感数据难以探测发现, 对实验结果可靠性存在一定影响,因此微地形变化也是一个重要的研究问题; (2) 假设研究时段土壤未发生 变化的问题。随着退耕还林(草)工程的实施, 植被不断恢复的同时,伴随着土壤肥力不断恢复,但本文中假 设土壤性质也不变,将土壤数据作为常量,使得研究结果具有一定偏差。因此,在今后研究中应该进一步考虑 微地形、土壤变化对土壤侵蚀的影响,使研究更加科学合理。

致谢 : 感谢西安科技大学测绘科学与技术学院周自翔副教授对本研究的帮助。

\section{参考文献 (References) :}

[ 1 ] Fu B J, Liu Y, Lü Y H, He C S, Zeng Y, Wu B F. Assessing the soil erosion control service of ecosystems change in the Loess Plateau of China. Ecological Complexity, 2011, 8(4): 284-293.

[ 2 ] 张琨, 吕一河, 傅伯杰, 尹礼唱, 于丹丹. 黄土高原植被覆盖变化对生态系统服务影响及其阈值. 地理学报, 2020, 75( 5) : 949-960.

[ 3 ] 赵文启, 刘宇, 罗明良, 汪亚峰, 吕一河. 黄土高原小流域植被恢复的土壤侵蚀效应评估. 水土保持学报, 2016, 30(5): 89-94.

[ 4 ] 郭明明. 黄土高塬沟壑区退耕草地沟头溯源侵蚀及形态演化特征 $[\mathrm{D}]$. 杨凌: 西北农林科技大学, 2016.

[ 5 ] 王文金金, 王文龙, 郭明明, 王天超, 康宏亮, 杨波, 赵满, 陈卓釒. 黄土高塬沟壑区植被恢复对沟头土壤团聚体特征及土壤可蚀性的影 响. 中国农业科学, 2019, 52(16): 2845-2857.

[ 6 ] 王志杰. 延河流域植被与侵蚀产沙特征研究 [D]. 咸阳: 中国科学院研究生院 (教育部水土保持与生态环境研究中心), 2014.

[ 7 ] 顾朝军. 黄土区土壤水文物理特性及流域产汇流机制变化对植被恢复的响应 [D ]. 杨凌: 西北农林科技大学, 2019.

[ 8 ] 程复. 黄土丘陵沟壑区生态恢复背景下土地利用变化对河川径流泥沙影响研究 [D]. 北京: 北京林业大学, 2011.

[ 9 ] 赵巧巧. 陕北黄土高原典型流域植被恢复状况及其与水沙变化的关系 [D]. 杨凌: 西北农林科技大学, 2019.

[10］王怡菲. 陕西省渭河流域生态修复绩效评价研究 [D ]. 杨凌: 西北农林科技大学, 2019.

[11] 陈浩. 黄土高原退耕还林前后流域土壤侵蚀时空变化及驱动因素研究 [D]. 杨凌: 西北农林科技大学, 2019.

[12] 焦菊英, 王宁, 杜华栋, 王东丽. 土壤侵蚀对植被发育演替的干扰与植物的抗侵蚀特性研究进展. 草业学报, 2012, 21(5): 311-318.

[13］王志印，曹建生. 中国北方土石山区植被恢复及其生态效应研究进展. 中国生态农业学报(中英文)，2019，27(9)：1319-1331.

[14] 寇萌. 黄土丘陵沟壑区抗侵蚀植物及其群落特征研究 $[D]$. 咸阳: 中国科学院研究生院 (教育部水土保持与生态环境研究中心), 2016.

［15］王超军, 吴锋, 赵红荵, 陆胜寒. 时间信息熵及其在植被覆盖时空变化遥感检测中的应用. 生态学报, 2017, 37(21): 7359-7367.

[16] 谢宝妮. 黄土高原近 30 年植被覆盖变化及其对气候变化的响应 $[D]$. 杨凌: 西北农林科技大学, 2016.

[17] 杨丽红. 近 50 年延河水沙特征对流域降水一植被动态响应研究 [D]. 西安: 陕西师范大学, 2014.

[18] 刘可, 杜灵通, 侯静, 胡悦, 朱玉果, 宫菲. 近 30 年中国陆地生态系统 NDVI 时空变化特征. 生态学报, 2018, 38(6): 1885-1896.

[19] 赵安周, 刘宪锋, 朱秀芳, 潘耀忠, 陈抒晨. 2000-2014 年黄土高原植被覆盖时空变化特征及其归因. 中国环境科学, 2016, 36(5)： 1568- 1578 .

[20] Sun W Y, Song X Y, Mu X M, Gao P, Wang F, Zhao G J. Spatiotemporal vegetation cover variations associated with climate change and ecological restoration in the Loess Plateau. Agricultural and Forest Meteorology, 2015, 209-210: 87-99.

[21］张含玉, 方怒放, 史志华. 黄土高原植被覆盖时空变化及其对气候因子的响应. 生态学报, 2016, 36(13) : 3960-3968.

[22］高江波，焦珂伟，吴绍洪. 1982-2013 年中国植被 NDVI 空间异质性的气候影响分析. 地理学报, 2019, 74(3) : 534-543.

[23] 林峰, 陈兴伟, 姚文艺, 方艺辉, 邓海军, 吴杰峰, 林炳青. 基于 SWAT 模型的森林分布不连续流域水源涵养量多时间尺度分析. 地理学 报, 2020, 75(5): 1065-1078.

[24] 降亚楠, 王蕾, 魏晓妹, 丁星臣. 基于 SWAT 模型的气候变化对泾河径流量的影响. 农业机械学报, 2017, 48(2): 262-270.

[25] 龚珺夫. 无定河流域水沙变化及侵蚀能量空间分布研究 [D]. 西安: 西安理工大学, 2018.

[26] 杨晓楠. 黄土高原多尺度景观格局对径流及输沙过程的影响 [D]. 杨凌: 西北农林科技大学, 2019. 
[27］王纪伟, 孙光, 罗遵兰, 刘康. 汉江上游森林生态系统土壤保持服务功能研究. 环境科学与技术, 2015, 38(12): 291-297.

[28] 吴娜, 宋晓谕, 康文慧, 邓晓红, 胡想全, 石培基, 刘玉卿. 不同视角下基于 InVEST 模型的流域生态补偿标准核算一一以渭河甘肃段为 例. 生态学报, 2018, 38(7): 2512-2522.

[29] 江忠善, 郑粉莉, 武敏. 中国坡面水蚀预报模型研究. 泥沙研究, 2005, (4): 1-6.

[30] 韩永伟, 高吉喜, 王宝良, 刘成程, 汪军, 拓学森. 黄土高原生态功能区土壤保持功能及其价值. 农业工程学报, 2012, 28(17)：78$85,294$.

[31］龚溪, 曹铭昌, 孙孝平, 乐志芳, 李双, 徐海根. 武夷山市生态系统服务价值评估. 生态与农村环境学报, 2017, 33(12)：1094-1101.

[32] 岳本江. 延河流域水沙演变及对土地利用/覆被变化的响应 [D ]. 咸阳: 中国科学院研究生院 (教育部水土保持与生态环境研究中 心), 2015 .

[33] 王重洋. 中国植被物候时空变化特征研究 [D]. 福州: 福州大学, 2014.

[34] 刘红兵. 近 30 年我国北方 13 省植被生长季变化分析 $[\mathrm{D}]$. 兰州: 西北师范大学, 2016.

［35］张肿, 雷田旺, 宋佃星. 黄土高原植被覆盖与土壤湿度的时滞关联及时空特征分析. 生态学报, 2018, 38(6) : 2128-2138.

[36] 李建丽. 基于“源一汇”理论的延河流域景观格局与土壤侵蚀的关系研究 [D ]. 西安: 陕西师范大学, 2014.

[37］宋敏敏, 张青峰, 吴发启, 吴秉校, 吴驳. 基于 NDVI 的延河流域时空演变分析. 水土保持研究, 2017, 24(4): 6-11.

[38] 邓伟, 刘德绍, 唐燕秋, 齐静. 三峡库区土壤保持重要区(重庆段)生态系统服务功能空间分异特征. 三峡生态环境监测, 2017, 2(2)： 9-18.

[39］雒新萍. 近 25a 来秦巴山区植被 NDVI 时空变化及其对区域气候的响应 [D]. 西安: 西北大学, 2009.

[40] 李双成, 王理, 朱文博, 张津, 刘娅, 高阳, 王阳, 李琰. 基于空间与区域视角的生态系统服务地理学框架. 地理学报, 2014, 69(11)： 1628-1639.

[41］刘月, 赵文武, 贾立志. 土壤保持服务: 概念、评估与展望. 生态学报, 2019, 39(2)：432-440.

[42］曹斌挺, 焦菊英, 王志杰, 魏艳红, 李玉进. 2013 年延河流域特大暴雨下的滑坡特征. 水土保持研究, 2015, 22(6)：103-109.

[43] 张乐涛. 基于侵蚀能量的径流输沙尺度效应研究 [D ]. 咸阳: 中国科学院研究生院 (教育部水土保持与生态环境研究中心), 2016.

[44] 邹厚远, 焦菊英. 黄土丘陵沟壑区抗侵蚀植物的初步研究. 中国水土保持科学, 2010, 8(1)：22-27.

[45] 张小彦, 焦菊英, 王宁, 贾燕锋. 黄土丘陵沟壑区土壤侵蚀对 3 种高属种子有效性的影响. 水土保持研究, 2010, 17(1): 56-61.

[46］周日平. 黄土高原典型区土壤保持服务效应研究. 国土资源遥感, 2019, 31(2)：131-139.

[47] 李佳蕾, 孙然好, 熊木齐, 杨国成. 基于 RUSLE 模型的中国土壤水蚀时空规律研究. 生态学报, 2020, 40(10): 3473-3485.

[48］冯强, 赵文武. USLE/RUSLE 中植被覆盖与管理因子研究进展. 生态学报, 2014, 34(16) : 4461-4472.

[49] 高海东, 李占斌, 李鹏, 贾莲莲, 徐国策, 任宗萍, 庞国伟, 赵宾华. 基于土壤侵蚀控制度的黄土高原水土流失治理潜力研究. 地理学报, 2015, 70(9) : 1503-1515.

[50］史志华, 宋长青. 土壤水蚀过程研究回顾. 水土保持学报, 2016, 30(5): 1-10.

[51] 谢云，岳天雨. 土壤侵蚀模型在水土保持实践中的应用. 中国水土保持科学，2018，16(1):25-37. 